\section{Lettuce Yield and Quality When Grown in High Tunnel and Open-Field Production Systems Under Three Diverse Climates}

\author{
Russell W. Wallace ${ }^{1,5}$, Annette L. Wszelaki², Carol A. Miles ${ }^{3}$, \\ Jeremy S. Cowan ${ }^{3}$, Jeffrey Martin ${ }^{2}$, Jonathan Roozen ${ }^{3}$, \\ Babette Gundersen ${ }^{4}$, and Debra A. Inglis ${ }^{4}$
}

ADDITIONAL INDEX WORDs. protective covering, season extension, microclimate, organic, plastic mulch, Lactuca sativa

SUMMARY. Field studies were conducted during 2010 and 2011 in Knoxville, TN; Lubbock, TX; and Mount Vernon, WA; to compare high tunnel and open-field organic production systems for season extension and adverse climate protection on lettuce (Lactuca sativa) yield and quality. The climates of these locations are diverse and can be typified as hot and humid (Knoxville), hot and dry (Lubbock), and cool and humid (Mount Vernon). In both years, 6-week-old lettuce seedlings of 'New Red Fire' and 'Green Star' (leafy type), 'Adriana' and 'Ermosa' (butterhead type), and 'Coastal Star' and 'Jericho' (romaine type) were transplanted in the late winter or early spring into subplots covered with black plastic and grown to maturity (43 to $\mathbf{6 5}$ days). Lettuce harvest in Knoxville occurred at 50 to $\mathbf{6 2}$ days after transplanting (DAT), with open-field lettuce harvested an average of 9 days earlier compared with high tunnel plots both years $(P>0.0001)$. The earlier than anticipated harvests in the open-field in Knoxville in 2010 were due to lettuce bolting. In Lubbock, high tunnel lettuce was harvested an average 16 days earlier in 2010 compared with open-field lettuce $(P>0.0001)$, while in 2011 , high temperatures and bolting required that open-field lettuce be harvested 4 days earlier than lettuce grown in high tunnels. On average, lettuce cultivars at Mount Vernon matured and were harvested 56 to 61 DAT in 2010 and 54 to 64 DAT in 2011 with no significant differences between high tunnel and open-field production systems. Total and marketable yields at Mount Vernon and Lubbock averaged across cultivars were comparable in both high tunnel and open-field plots. At Knoxville, although total yields were significantly higher $(P>0.0062)$ in high tunnels than open-field plots, incidence of insect, disease, and physiological damage in high tunnel plots reduced lettuce quality and marketable yield $(P>0.0002)$. Lettuce head length:diameter ratio (LDR) averaged across cultivars was equal between high tunnel and the open field at all three locations. High tunnel production systems offer greater control of environments suitable for lettuce production, especially in climates like Knoxville and Lubbock where later-planted open-field systems may be more susceptible to temperature swings that may affect lettuce quality. These results suggest that although high tunnel culture alone may influence lettuce yield and quality, regional climates likely play a critical role in determining the impact of these two production systems on marketable lettuce yields.

$\mathrm{H}$ igh tunnels are large, framed structures covered with a single or double layer of greenhouse-grade plastic with no electrical or ventilation systems and are typically used to produce high-value specialty crops including lettuce and other leafy greens (Knewtson et al., 2010; Lamont, 2009). High tunnels are employed as crop growth enhancers, providing climate protection during severe weather conditions and enabling season extension (Lamont et al., 2002; Reeves and Drost, 2012). In the United States, high tunnels have not previously been as widely used in horticulture production compared with many other countries (Carey et al., 2009; Rader and Karlsson, 2006; Wittwer, 1993). Recently however, improved technology, interest in local food production, and the availability of federal cost-sharing funds have stimulated interest in high tunnels among specialty crop growers. Corresponding research and extension efforts have similarly increased throughout the United States (Carey et al., 2009; U.S. Department of Agriculture, 2011).

High-value crops including fall/ winter or early spring-grown spinach (Spinacia oleracea) and brassica greens (Brassica sp.), leafy and head lettuce (Lactuca sativa), and various herbs are commonly grown in high tunnels, especially in regions where climate protection is needed for season extension. Tomato (Solanum lycopersicum) and pepper (Capsicum annuиm), small fruit, tree fruit, and ornamental and cut flower production in high tunnels is also expanding in the United States (Demchak, 2009; Lang, 2009; Wien, 2009a). High tunnel production has been popular for several decades in the north-central and northeastern United States, while other regions including the southeastern, midsouthern, and northwestern United States have only recently adopted this technology (Carey et al., 2009). The moderate climates during the fall and winter months in the southern and maritime Pacific northwestern United States may have initially contributed to the slow adoption of high tunnels in those regions. However, adverse weather has propelled grower interest in the adoption of tunnels as a means of added insurance for successful production of specialty crops.

Lettuce is harvested year-round within the United States, occurring in the early spring and late fall in northern climates, and during the winter months in southern latitudes (Dufault et al., 2006). Specific regional production cycles may vary depending

\begin{tabular}{llll}
\hline $\begin{array}{l}\text { Units } \\
\text { To convert U.S. to SI, } \\
\text { multiply by }\end{array}$ & U.S. unit & SI unit & $\begin{array}{l}\text { To convert SI to U.S., } \\
\text { multiply by }\end{array}$ \\
\hline $\mathrm{l}$ & $\mathrm{cbar}$ & $\mathrm{kPa}$ & $\mathrm{l}$ \\
0.0731 & $\mathrm{fl} \mathrm{oz} / \mathrm{acre}$ & $\mathrm{L} \cdot \mathrm{ha}^{-1}$ & 13.6840 \\
0.3048 & $\mathrm{ft}$ & $\mathrm{m}$ & 3.2808 \\
3.7854 & $\mathrm{gal}$ & $\mathrm{L}$ & 0.2642 \\
2.54 & inch(es) & $\mathrm{cm}$ & 0.3937 \\
25.4 & inch $(\mathrm{es})$ & $\mathrm{mm}$ & 0.0394 \\
0.4536 & $\mathrm{lb}$ & $\mathrm{kg}$ & 2.2046 \\
0.0254 & $\mathrm{mil}$ & $\mathrm{mm}$ & 39.3701 \\
1.6093 & $\mathrm{mph}$ & $\mathrm{km} \cdot \mathrm{h}^{-1}$ & 0.6214 \\
70.0532 & $\mathrm{oz} / \mathrm{acre}$ & $\mathrm{g} \cdot \mathrm{ha}^{-1}$ & 0.0143 \\
$\left({ }^{\circ} \mathrm{F}-32\right) \div 1.8$ & ${ }^{\circ} \mathrm{F}$ & ${ }^{\circ} \mathrm{C}$ & $\left({ }^{\circ} \mathrm{C} \times 1.8\right)+32$ \\
& & &
\end{tabular}


on day/night temperatures, sunlight intensity, daylength, humidity, wind speeds, and elevation among other factors. During the winter months, high tunnels provide microclimates suitable for season extension allowing growers to plant lettuce earlier in the season, later in the season, or both. Optimizing the utilization of these microclimates can improve crop yield and quality (Zhao and Carey, 2009).

Depending on location, lettuce production may be limited during early spring and summer months because of unfavorable temperatures that increase the risk of bolting, tip burn, and leaf bitterness (Simonne et al., 2002; Zhao and Carey, 2009). Optimal growing temperature for lettuce is $18.5^{\circ} \mathrm{C}$, though heat-tolerant cultivars may tolerate higher temperatures provided that night-time temperatures are cooler (Dufault et al., 2006; Zhao and Carey, 2009). However, Dufault et al. (2006) reported that as planting dates progressed toward warmer temperatures and longer daylength, lettuce yield and quality were negatively affected. Flower initiation generally occurs between 21 and $27^{\circ} \mathrm{C}$; however, higher temperatures coupled with warm nights may initiate premature bolting and increase the potential for physiological tipburn (Maynard and Hochmuth, 1997; Simonne et al., 2002). Both disorders will decrease lettuce quality and marketability.

Winter and early spring lettuce production using high tunnels in southern regions may potentially mitigate physical/adverse risks associated with planting early open-field crops,

Funding for this project provided by NIFA SCRI SREP for 'Biodegradable Mulches for Specialty Crops Produced Under Protective Covers' (Award No. 2009-51181-05897).

Mention of product trade names does not imply an endorsement of the products used or criticism of similar ones not used.

${ }^{1}$ Department of Horticultural Sciences, Texas AgriLife Research \& Extension Center, 1102 East FM 1294, Lubbock, TX 79403

${ }^{2}$ Department of Plant Sciences, University of Tennessee, 252 Ellington Plant Sciences Building, Knoxville, TN 37996

${ }^{3}$ Department of Horticulture and Landscape Architecture, Washington State University, Mount Vernon NWREC, 16650 State Route 536, Mount Vernon, WA 98273

${ }^{4}$ Department of Plant Pathology, Washington State University, Mount Vernon NWREC, 16650 State Route 536, Mount Vernon, WA 98273

${ }^{5}$ Corresponding author. E-mail: rwwallace@ag.tamu. edu. and the cooler temperatures typical of earlier plantings in high tunnels allows for improved lettuce quality and yield (Zhao and Carey, 2005). In regions similar to the Texas High Plains, lettuce production is extremely limited because of severe climatic factors, including high temperatures, hail, high winds, and blowing dust, which are common from January through May. In contrast, shelter from excessive rainfall and soil moisture may be needed for lettuce protection in the maritime Pacific Northwest. Although enhanced high tunnel crop production offers growers the potential to increase sales and marketing, microclimate differences in tunnels may influence yield by decreasing potential for tipburn or bolting (Zhao and Carey, 2009). Adverse high tunnel microclimates may trigger both genetic and internal physiological mechanisms within individual cultivars, influencing overall productivity (Dufault et al., 2006). High tunnel microclimates may also create environments that are also unintentionally favorable to plant pathogens, insects, and weeds. Given these concerns, the objective of this research project was to employ a systems approach for comparing the production of six spring-planted lettuce cultivars for yield and quality when grown in high tunnels or open-field production systems located under three contrasting regions within the United States where high tunnel lettuce production has until now been less common.

\section{Materials and methods}

The experimental field trials were conducted during late Winter and Spring 2010 and 2011 in high tunnel and open-field organic production systems located at the University of Tennessee, East Tennessee AgResearch and Education Center Organic Crops Unit in Knoxville (lat. $35.96^{\circ} \mathrm{N}$, long. $83.92^{\circ} \mathrm{W}$ ); the Texas AgriLife Research \& Extension Center in Lubbock (lat. $33.57^{\circ} \mathrm{N}$, long. $101.85^{\circ} \mathrm{W}$ ); and the Washington State University Northwestern Washington Research \& Extension Center in Mount Vernon (lat. $48.42^{\circ} \mathrm{N}$, long. $122.33^{\circ} \mathrm{W}$ ). High tunnel types (four at each location) were selected based on general climatic factors and grower preferences. The high tunnel at Knoxville was a Windjammer Series 5000 Cold Frame (Golden Pacific Structure,
Cincinnati, OH); at Lubbock, a Clear$\mathrm{Span}^{\mathrm{TM}}$ Colossal high tunnel (ClearSpan Fabric Structures, South Windsor, CT); and at Mount Vernon, a Haygrove Solo high tunnel (Haygrove, Redbank, Ledbury, UK). The plastic coverings on the high tunnels were Durafilm Super 4 (AT Films, Edmonton, AB, Canada) with $92 \%$ optical transmission at Knoxville; PolyMax Clear Woven Greenhouse Covering (ClearSpan Fabric Structures) with $88 \%$ light transmission at Lubbock; and, Tufflite IV (Berry Plastics, Evansville, IN) with unspecified light transmission at Mount Vernon. High tunnels at Knoxville and Lubbock measured $30 \times 96 \mathrm{ft}$ and at Mount Vernon measured $28 \times 120 \mathrm{ft}$.

Six commercial lettuce cultivars were selected based on their characteristics for slow bolting, and heat and physiological tip burn tolerance, traits needed for improved lettuce quality production in most southern regions. Two cultivars each of leafy (New Red Fire and Green Star), butterhead (Ermosa and Adriana), and romaine (Jericho and Coastal Star) (Johnny's Selected Seeds, Winslow, ME) types were selected for evaluation. Greenhouse seeding and transplanting dates varied by state and year, and are listed in Table 1 . Seeding and transplanting dates at each site were determined by general local practices within each region. However, at Lubbock, high tunnels were first set up in Winter 2010 but seasonal high winds prohibited covering the frames for several months; therefore, seeding and transplanting was delayed from that anticipated by $\approx 4$ weeks. At all three locations, hardened 6week-old lettuce seedlings were hand transplanted into subplots measuring $3 \times 14 \mathrm{ft}$ in both high tunnel and open-field plots. Seedlings were transplanted at Knoxville on 11 Mar. and 14 Apr. in 2010, and $23 \mathrm{Feb}$. and 1 Apr. during 2011 in high tunnel and open-field plots, respectively. At Lubbock, lettuce was transplanted in both high tunnel and in the open-field plots on 5 Apr. in 2010, and 2 Mar. and 30 Mar. during 2011 in high tunnels and in the open field, respectively. At Mount Vernon, lettuce was transplanted both years on 22 Apr. in both high tunnels and open-field plots. Six subplots (one per cultivar) were assigned within each main plot and transplanted with 28 plants per cultivar 
Table 1. Seeding, transplanting, and harvest dates for lettuce cultivars planted in high tunnel (HT) and open-field (OF) production systems in three regions of the United States (Knoxville, TN; Lubbock, TX; and Mount Vernon, WA) in 2010 and 2011.

\begin{tabular}{|c|c|c|c|c|c|c|}
\hline \multirow[b]{2}{*}{ Action } & \multicolumn{2}{|c|}{ Knoxville } & \multicolumn{2}{|c|}{ Lubbock } & \multicolumn{2}{|c|}{ Mount Vernon } \\
\hline & HT & OF & HT & OF & HT & $\mathrm{OF}$ \\
\hline \multicolumn{7}{|l|}{2010} \\
\hline Transplant & 11 Mar. & 14 Apr. & 5 Apr. & 5 Apr. & 22 Apr. & 22 Apr. \\
\hline First harvest & 10 May & 3 June & 12 May & 7 June & 15 June & 15 June \\
\hline Final harvest & 27 May & 3 June & 19 May & 8 June & 29 June & 29 June \\
\hline Transplant & 23 Feb. & 1 Apr. & 2 Mar. & 30 Mar. & 22 Apr. & 22 Apr. \\
\hline First harvest & 12 Apr. & 13 May & 12 Apr. & 11 May & 10 June & 16 June \\
\hline Final harvest & 27 Apr. & 1 June & 27 Apr. & 18 May & 24 June & 27 June \\
\hline
\end{tabular}

(20 in Knoxville only in 2010 because of seedling issues) in two staggered rows per bed (12 inches in- and between-rows). During the experiments, the high tunnels were vented as needed by location, typically when internal temperatures reached $85^{\circ} \mathrm{F}$, and high tunnels were fully closed when internal temperatures reached below $68^{\circ} \mathrm{F}$ and/or when wind speeds reached $15 \mathrm{mph}$ and over.

All plots were monitored weekly, and fertilizer, irrigation, and pest management were applied as needed at each location. Fertilizer application at Knoxville included pre-plant organic fertilizer (soybean meal $7 \mathrm{~N}-$ $0.9 \mathrm{P}-0.8 \mathrm{~K}$; Foothills Farmers CoOp, Maryville, TN); at Lubbock, composted cattle manure plus cotton burrs $(3 \mathrm{~N}-0.4 \mathrm{P}-0.8 \mathrm{~K}$; Soil Mender Products, Tulia, TX); and at Mount Vernon (Par 4 9N-1.3P-5.8K; North Pacific Ag Products, Portland, OR). The subplots were rototilled before a single drip line at Knoxville and Mount Vernon (T-Tape, low flow, 12-inch emitter spacing; TSystems International, San Diego, CA) and at Lubbock (Typhoon 636 $0125 \mathrm{~F}, 0.25 \mathrm{gal} / \mathrm{h}, 12$-inch emitter spacing; Netafim, Tel Aviv, Israel) was laid. Drip lines were placed in the center of each plot beneath a single layer of black polyethylene plastic mulch (1.0 mil embossed; Berry Plastics). The mulch was laid flat at Knoxville and Lubbock, and onto preshaped beds with a 5 -ft center at Mount Vernon, using a tractor-mounted mulch layer at each location.

Single nozzle hand-held sprayers were used for pest control at all three field sites as needed. At Knoxville, Bacillus thuringiensis ssp. kurstaki strain ABTS-35l and pyrethrin (Pyganic Crop Protection EC; McLaughlin Gormley King, Minneapolis, MN) were applied at $16 \mathrm{fl} \mathrm{oz} /$ acre for green peach aphid (Myzus persicae) control; potassium salts of fatty acids (Natural Guard ${ }^{\circledR}$ Insecticidal Soap; Voluntary Purchasing Group, Bonham, TX) and $B$. thuringiensis were applied at Lubbock at $2 \% \mathrm{v} / \mathrm{v}$ rate and $10 \mathrm{oz} /$ acre, respectively, to control onion thrips (Thrips tabaci), green peach aphid, and greenhouse whiteflies (Trialeurodes vaporariorum); and pyrethrin was applied at Mount Vernon $66 \mathrm{fl} \mathrm{oz} /$ acre to control lettuce aphid (Nasonovia ribisnigri) and western flower thrips (Frankliniella occidentalis). Seedlings were damaged by black cutworm larvae (Agrotis ipsilon) in high tunnel plots at Knoxville and by slugs (Agriolimax reticulatus) in both high tunnel and open-field plots at Mount Vernon. Damaged seedlings at Knoxville and Mount Vernon were replaced as-needed up to 3 weeks following transplanting. One week after transplanting, extra lettuce plants at Mount Vernon were removed from seedling trays and potted to 4 -inch pots and fertilized regularly so their size was somewhat comparable to those in the plots. The dates and numbers of the replacement transplants were recorded, and there were no differences in at-harvest plant size as a result of transplant date. No plants were replaced at Lubbock.

Soil moisture was monitored weekly at all three locations using sensors (Watermark model 200SS; Irrometer, Riverside, CA) placed 6inches deep beneath the plastic mulch. Lettuce was irrigated once $(0.25$ inch $)$ or twice per week as needed based on the soil moisture evaluations (when sensors reached a range of 25 to 30 cbar) at Knoxville and Mount Vernon, beginning at transplanting and continuing until harvest. At Lubbock, lettuce was irrigated twice weekly with 1.0 inch per application, then three times weekly beginning 4 weeks after transplanting because of Lubbock's higher air temperatures and lower humidity. Crops were fertilized biweekly through the drip system with liquid fish at Knoxville (Schafer's Liquid Fish $2 \mathrm{~N}-0.9 \mathrm{P}-0.2 \mathrm{~K}$; Schafer Fisheries, Thomson, IL) and Lubbock (Fertilome Fish Emulsion Fertilizer 5N-0.4P$0.8 \mathrm{~K}$, Voluntary Purchasing Group), and liquid fertilizer (Converted Organics Fertilizer $5 \mathrm{~N}-0.9 \mathrm{P}-0.8 \mathrm{~K}$; Converted Organics, Boston, MA) at Mount Vernon.

Growing environments for all three locations are shown in Table 2. Elevation at Knoxville and Lubbock is 886 and $3250 \mathrm{ft}$, respectively, while site elevation at Mount Vernon is near sea level $(23 \mathrm{ft})$. Soil $\mathrm{pH}$ at the three locations ranged from 6.2 (Mount Vernon) to 7.4 (Lubbock); percent organic matter was greatest at Mount Vernon $(3.1 \%)$, but averaged $1.25 \%$ at Knoxville and Lubbock. Microclimate data were recorded at Knoxville and Lubbock in 2011 only, as weather monitoring equipment (HOBO Weather Station Data Loggers; Onset Computer, Bourne, MA) arrived too late in 2010 for use in the high tunnels. At Mount Vernon, the data loggers were placed near the center within one high tunnel and open-field plot both years. Because of the high costs of the weather monitoring equipment, only one high tunnel and open-field plot 
Table 2. Growing environments for lettuce cultivars planted in high tunnel (HT) and open-field (OF) production systems in three regions of the United States (Knoxville, TN; Lubbock, TX; and Mount Vernon, WA) in 2010 and 2011.

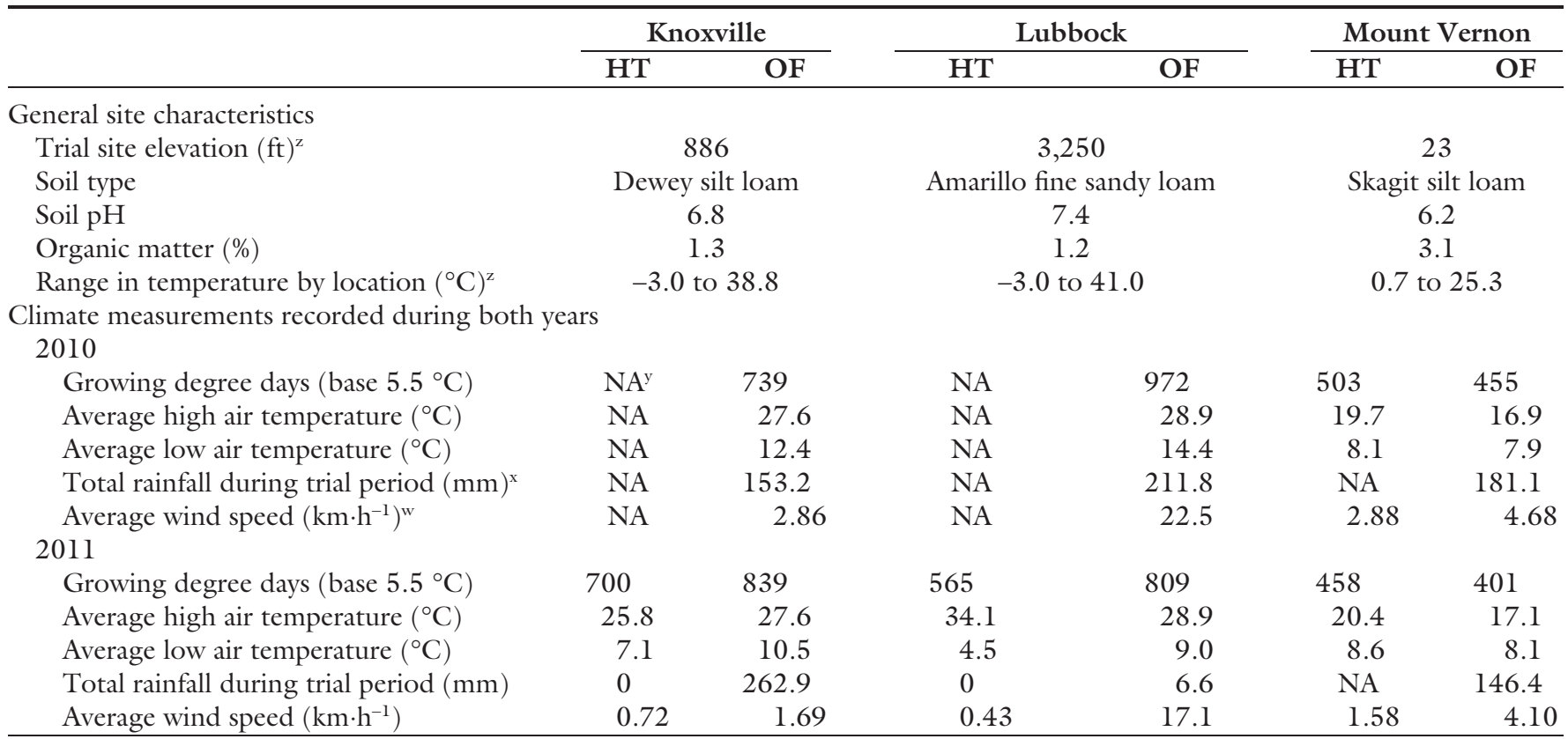

${ }^{2} \mathrm{l} \mathrm{ft}=0.3048 \mathrm{~m},\left(1.8 \times{ }^{\circ} \mathrm{C}\right)+32={ }^{\circ} \mathrm{F}$.

${ }^{\prime} \mathrm{NA}=$ data not available; in Knoxville and Lubbock, data loggers were received and installed after lettuce trials were completed in 2010.

${ }^{x}$ In 2010, a rain event at Lubbock of $116.5 \mathrm{~mm}$ occurred 16 to 18 Apr. and resulted in significant flooding and standing water in HT plots; $1 \mathrm{~mm}=0.0394$ inch.

${ }^{w}$ High wind gust speeds for open-field plots at Lubbock were 98 and $109 \mathrm{~km} \cdot \mathrm{h}^{-1}$ in 2010 and $201 \mathrm{l}$, respectively, and averaged $44 \mathrm{~km} \cdot \mathrm{h}^{-1} \mathrm{during}$ both seasons; $1 \mathrm{~km} \cdot \mathrm{h}^{-1}=$ $0.6214 \mathrm{mph}$.

were monitored at each site. Although minimal variation among high tunnels may have existed at each field site, there likely would not have been differences among the climates of the open-field plots given their close proximity. Meteorological observations included growing degree days (GDD base $5.5^{\circ} \mathrm{C}$ ), average high/low air temperatures, rainfall, and wind and gust speeds recorded at $15-\mathrm{min}$ intervals.

Lettuce cultivars were harvested when the heads felt firm and were $\approx 12$ inches in diameter when bunched by hand (Table 1). Bolting in some cultivars grown at Knoxville and Lubbock occurred earlier than the anticipated maturity date; therefore, for those specific cultivars, entire subplots were harvested collectively. Total number and head weight by subplot were recorded before sorting into marketable and non-marketable categories. Marketable heads were weighed with the outer, non-marketable leaves removed. Finally, four marketable heads from each subplot were randomly selected and evaluated for head length and diameter. Non-marketable heads were sorted by disease [soft rot (Erwinia carotowora), grey mold (Botrytis cinerea), and lettuce drop (Sclerotinia sclerotiorum)] or by physiological disorders (bolting, tip burn, and misshapen heads).

The studies were conducted with production system (high tunnel or open field) as main plots and lettuce cultivars as subplot treatments at all three locations. All data were subjected to analysis of variance (PROC MIXED, SAS version 9.2; SAS Institute, Cary, NC). At Knoxville and Lubbock, because of space limitations, data were analyzed as a completely randomized split-plot design. At Mount Vernon, data were analyzed as a randomized complete block split-plot design. Statistical analysis at all locations compared production system (main plots), cultivars (subplots), and production system $\times$ cultivar interactions. Means were separated using Fisher's least significant difference test $(P>0.05)$. Because of the moderate but necessary differences in experimental methodology (planting dates, soils, fertilizers, etc.) between the sites, data were analyzed separately for each state but are presented together in tables for ease of reporting.

\section{Results and discussion}

ENVIRONMENTAL DIVERSITY BETWEEN LOCATIONS. Climate and soil differences may influence fresh market crop production, including lettuce yield and quality (Dufault, et al., 2006; Lamont, 2009). Early plant exposure to increasing irradiance, temperatures, and daylengths has been found to significantly reduce lettuce quality because of factors such as bolting (Dennis and Dulforce, 1974). Reduced lettuce yield and quality may also be associated with environmental stresses (high temperatures and winds) during later crop growth, or from damaging diseases and insect pests (Simonne et al., 2002; Zhao and Carey, 2009). As a cool-season vegetable, lettuce cultivar selection (genotype) and time of transplanting are critical to successful quality production (Dufault et al., 2006; Rader and Karlsson, 2006).

Growing environments also contribute to differences in lettuce yield and quality (Rader and Karlsson, 2006). In this study, open-field and high tunnel environments varied between the three locations for site elevation, soil type, GDD (daily accumulated heat units), and average wind speed and air temperature (Table 2). Although microclimates were unable to be monitored inside high tunnels at Knoxville and Lubbock during 2010 , in the open field there were 
739 and 972 GDD accumulated, respectively, from the time of transplanting to harvest (Table 2). In 2011, 700 and 839 GDD (Knoxville), and 565 and 809 GDD (Lubbock) accumulated in high tunnel and open-field plots, respectively. As a result, $16 \%$ and $30 \%$ higher GDD accumulated in the open field for the two respective sites. Higher daytime temperatures resulting from the later transplant dates in the open field at Knoxville [36 d to harvest (DAT) average both years] and Lubbock (28 DAT, 2011 only) likely contributed to greater GDD accumulation in those plots.

GDD accumulation at Mount Vernon contrasted the Knoxville and Lubbock sites with $10 \%$ and $12 \%$ greater GDD accumulation recorded inside high tunnels during 2010 and 2011 , respectively, as compared with the open field (Table 2). Higher GDD accumulation inside high tunnels at Mount Vernon can be attributed to transplanting lettuce on the same day in both production systems, as well as higher $\left(3^{\circ} \mathrm{C}\right)$ average inside tunnel temperatures. Rader and Karlsson (2006) and Wien (2009b) both reported that air temperatures inside ventilated and non-ventilated high tunnels in Northern locations increased more rapidly during the day compared with outside temperatures, although spatial variation (location) within high tunnels could influence temperatures as much as $2{ }^{\circ} \mathrm{C}$. Similarly, Waterer and Bantle (2000) reported that GDD accumulated more rapidly in high tunnels compared with standard tunnels and the open field. When GDD was averaged across open fields only for both years from the time of transplanting to final harvest, overall daily accumulation at Knoxville, Lubbock, and Mount Vernon was 14.3, 16.0, and 6.7, respectively; indicating $53 \%$ and $58 \%$ higher daily GDD at Knoxville and Lubbock, respectively, compared with Mount Vernon. Average daily GDD accumulation for Mount Vernon in the high tunnel environment was 7.3 (both years), compared with Knoxville and Lubbock (2011 data only) at 11.1 and 10.1, respectively (an average $31 \%$ increase).

In 2010, the average high/low temperatures for open-field plots at Knoxville and Lubbock were similar, and 10 to $12{ }^{\circ} \mathrm{C}$ higher compared with Mount Vernon (Table 2). In addition to temperature modification, high tunnels are used to protect crops from weather extremes, including excessive rainfall or high winds (Lamont, 2009). Rainfall recorded at Knoxville in the open field during crop growth was $43 \%$ higher in 2011 compared with 2010 (Table 2). Above normal rainfall was recorded at Lubbock during 2010 , but only $6.6 \mathrm{~mm}$ fell in 2011 (a year of record heat and drought), while at Mount Vernon rainfall was similar during both growing seasons. Average wind speed at all three locations during crop production both years was minimal inside high tunnels and measured 0.43 to $2.88 \mathrm{~km} \cdot \mathrm{h}^{-1}$ (Table 2). The above zero wind speeds recorded inside high tunnels were a result of air movement when the sides, end panels, or both had been opened for heat ventilation. In open-field plots, wind speeds averaged across both years were 2.28 and $4.39 \mathrm{~km} \cdot \mathrm{h}^{-1}$ at Knoxville and Mount Vernon, respectively, about two to three times those recorded in high tunnels. Wind speed in the open field at Lubbock averaged $19.8 \mathrm{~km} \cdot \mathrm{h}^{-1}$, almost 46 times higher compared with the high tunnels. The meteorological data recorded at each location in this study illustrated the diversity in environments in which the six lettuce cultivars were evaluated and provided a basis for discerning potential influences on yield and quality.

Days to harvest. Comparing cultivars as averaged across production systems in 2010 showed a difference $(P<0.0001)$ between days to harvest (DTH), but only at Knoxville (Table 3). Comparison of production systems also showed that fewer days $(P<0.0001)$ were needed in the open field compared with high tunnels, again only at Knoxville. The earlier harvest time at Knoxville was due to premature bolting resulting from untimely and extended periods of high daytime temperatures before harvest. Similarly, at Lubbock, entire plots had to be harvested because of premature bolting from continuous daytime temperatures at $33{ }^{\circ} \mathrm{C}$.

In 2011, significant differences were observed among cultivars at Knoxville $(P<0.0001)$ and Lubbock $(P<0.0001)$, and among cultivars and between production systems at Mount Vernon $(P<0.0001$ and 0.0271 , respectively) (Table 3 ). Transplanting $34 \mathrm{~d}$ earlier in $2011 \mathrm{com}-$ pared with 2010 in high tunnels at Lubbock (Table 1) reduced premature bolting, although there was no interaction between cultivar and production system. At all three locations, harvest time differences between cultivars were largely attributed to lettuce type. Leafy cultivars (New Red Fire and Green Star) matured in 43 to $47 \mathrm{~d}$ at Knoxville and Lubbock, regardless of production system, while at Mount Vernon, an average of $60 \mathrm{~d}$ was needed to reach maturity. In the warmer climates at Knoxville and Lubbock, open-field lettuce was harvested in fewer days $(P<0.0001)$ compared with high tunnels (Table 3 ). Shorter harvest times in the open field at Lubbock and Knoxville were attributed to the later transplant dates followed by high temperatures, which contribute to rapid growth and an increased likelihood of bolting and tipburn (Dufault et al., 2006; Zhao and Carey, 2009). In the cooler maritime climate at Mount Vernon, the increased temperature within the high tunnels produced harvestable lettuce in fewer days compared with open-field production. Finally, interactions were observed both years at Knoxville $(P<$ 0.0001 ) where DTH by cultivar was influenced by the higher temperatures and later planting in the open field, and in 2011 at Mount Vernon because of the unexpected late maturity of Ermosa in the high tunnels.

Averaged across both years, fewer days were needed to reach physiological maturity, premature bolting, or both at Lubbock ( $46 \mathrm{~d}$ ), followed by Knoxville (54 d) and Mount Vernon $(60 \mathrm{~d})$. These differences indicate the potential impact the three diverse locations have on harvest times required for the cultivars evaluated. Planting lettuce in January or early February in open-field production at Lubbock and Knoxville can be risky because of damaging frosts or severe weather (winds and hail). Transplanting in January or early February inside tunnels at these locations could likely decrease premature bolting; however, cultivars may be more susceptible to cold temperature injury and DTH extended unless measures are taken to add supplemental heat.

The addition of supplemental heating/rowcovers are discussed in several reports evaluating environmental influences on crops grown inside or outside high tunnels with planting date variations. Dufault et al. (2006) reported that lettuce cultivars planted 
Table 3. Days to harvest for lettuce cultivars planted in high tunnel and open-field production systems in three regions of the U.S. (Knoxville, TN; Lubbock, TX; and Mount Vernon, WA) in 2010 and 2011.

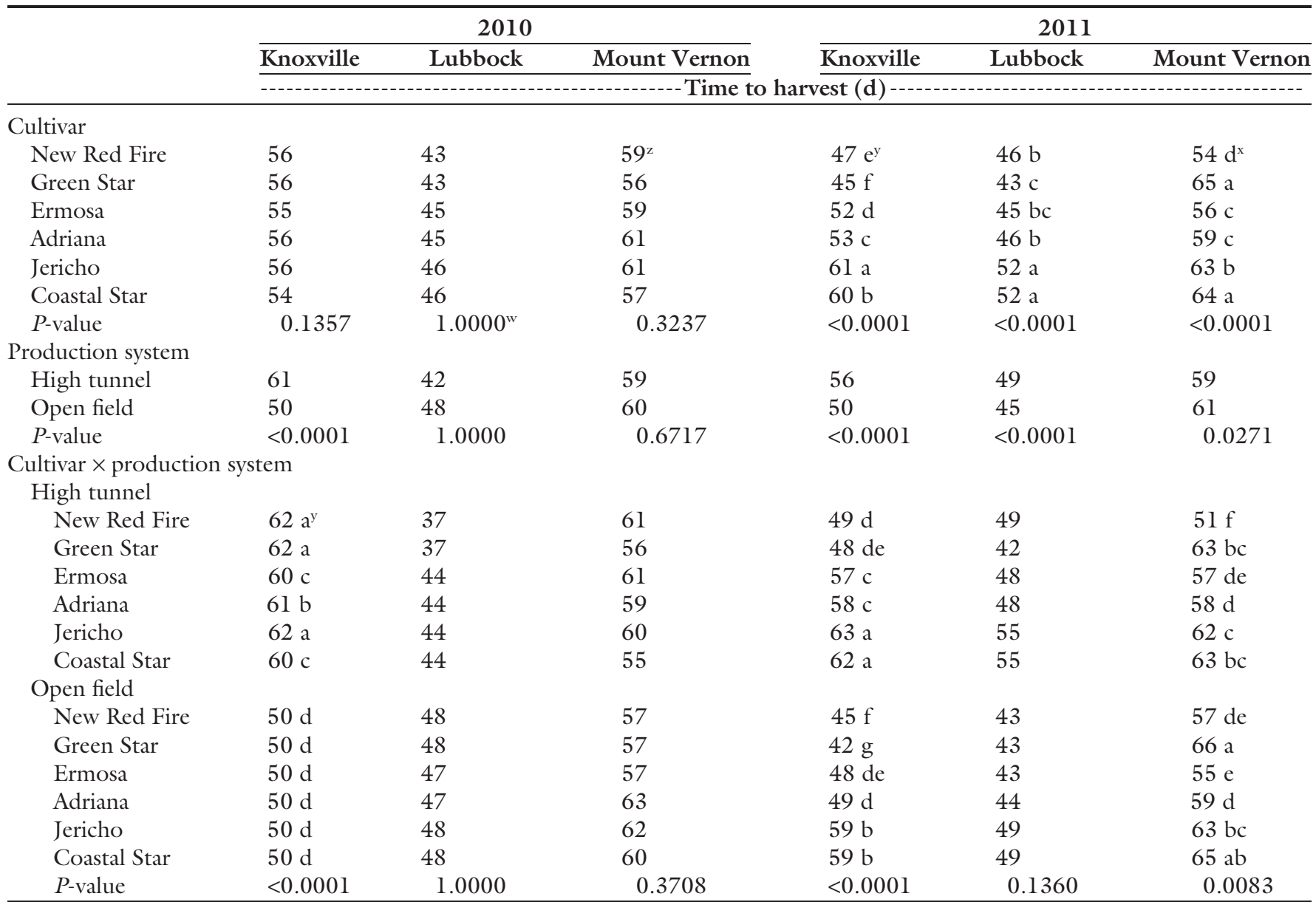

${ }^{2}$ Mount Vernon time to harvest data in 2010 were reciprocal transformed to meet the assumptions of normality. Non-transformed data are shown.

${ }^{y}$ Means within the same column for cultivar, production system, and cultivar $\times$ production followed by the same letter are not significantly different according to Fisher's protected least significant difference test at the 0.05 level.

'Mount Vernon time to harvest data in 2011 were square root transformed to meet the assumptions of normality. Non-transformed data are shown.

"Analysis stopped by SAS Procedures (SAS version 9.2; SAS Institute, Cary, NC) because of "infinite likelihood," as a result of harvesting all four replications by cultivar on the same day.

in open-field production in South Carolina from October to November or February to March reached maturity in $28 \%$ fewer days compared with those planted in December or January when temperatures were coldest. However, bolting was highest for planting dates outside the November-January timeframe. In contrast, delaying planting beyond those dates may risk yield reduction from high-temperature initiation of premature bolting, tipburn, or both (Dufault et al., 2006; Simonne et al., 2002). Rader and Karlsson (2006) report that yield of 'Two Star' lettuce planted on 15 July differed from that planted on 3 Aug., a difference of only 2 weeks. Manipulating the environment through supplemental heat or adding low tunnels inside high tunnels raised temperatures and improved early season tomato yield in a northern climate (Hunter, et al., 2012). In this study, differences in planting to harvest times between production systems in the southern climates of Knoxville and Lubbock resulted in higher season-to-season variability in the number of DTH since lettuce was exposed to multiple external influences (wind and heat). At Mount Vernon, the cooler climate allowed for consistent planting to harvest times both years.

YIELD. When averaged across production system in 2010, there were differences among cultivar total yields at both Knoxville $(P=0.0221)$ and Lubbock $(P<0.0001)$; while in 2011 , significant cultivar differences were observed at all three locations (Table 4). Similar to DTH, cultivar selection influenced total yield. 'Jericho' and 'Costal Star' (romaine) yields were highest at all locations each year, except at Knoxville in 2010. Lettuce production in either system had no effect on total yield at any location either year except at Knoxville ( $P=$ 0.0043 ) in 2010 .

Cultivar by production system interactions were observed both years for total yield at Knoxville ( $P=$ 0.0056 and $P<0.0001$, respectively) and at Lubbock $(P=0.0121)$ during 2010 (Table 4). At Knoxville, 'New Red Fire' yield was greater in high tunnels during 2010 but not in 2011 , whereas the opposite occurred with 'Green Star'. 'Ermosa' and 'Adriana' had higher yields inside high tunnels both years. At Lubbock in 2010, yields were higher in high tunnels for 'Ermosa' and 'Adriana' when compared with open-field production. There were no interactions for 
Table 4. Total yield of lettuce cultivars planted in high tunnel and open-field production systems in three regions of the United States (Knoxville, TN; Lubbock, TX; and Mount Vernon, WA) in 2010 and 2011.

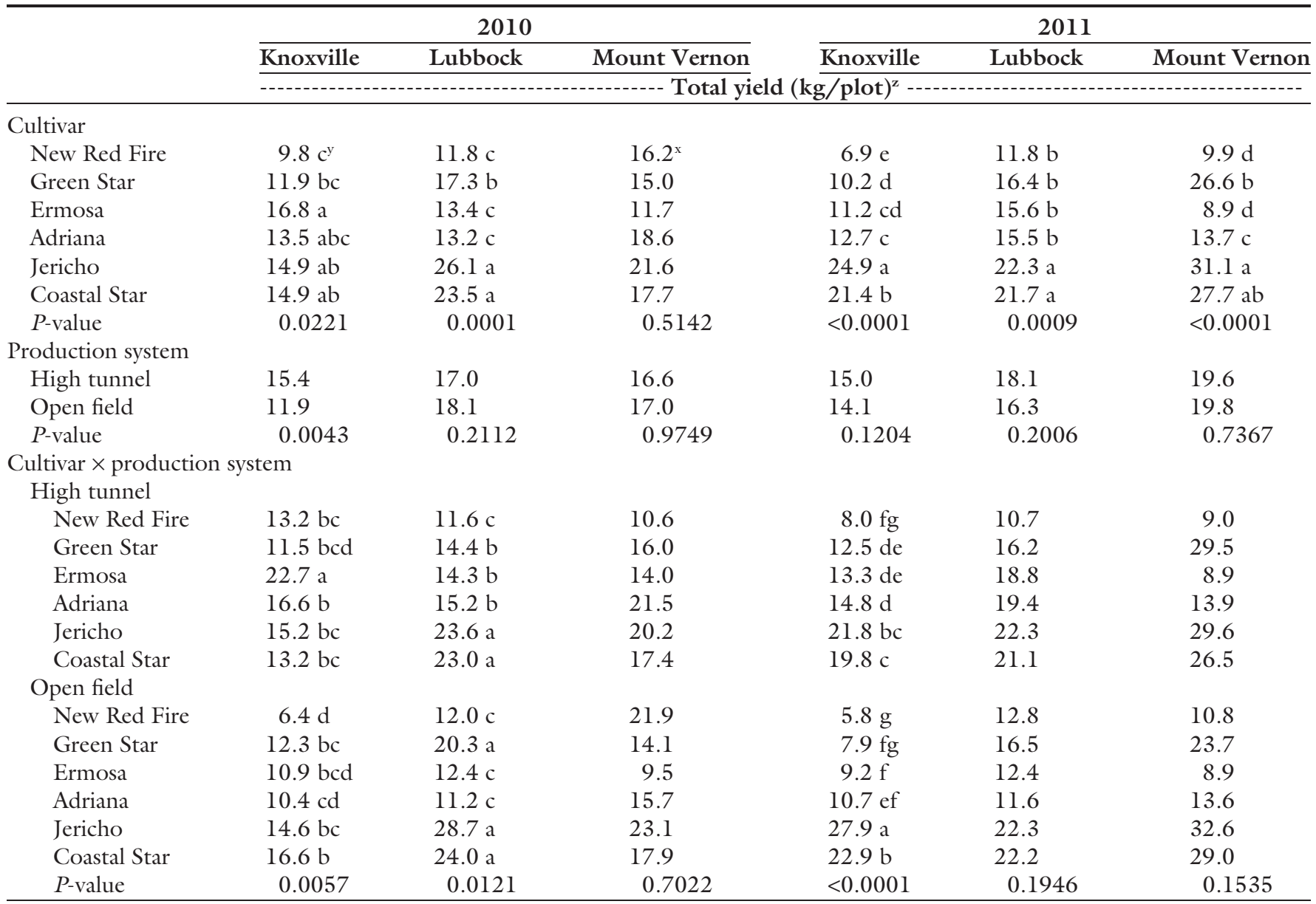

${ }^{\mathrm{z}} \mathrm{l} \mathrm{kg}=2.2046 \mathrm{lb}$.

${ }^{y}$ Means within the same column for cultivar, production system, and cultivar $\times$ production followed by the same letter are not significantly different according to Fisher's protected least significant difference test at the 0.05 level.

${ }^{x}$ Mount Vernon total yield data for 2010 and 2011 were $\log _{10}$ transformed to meet the assumptions of normality. Data presented in this table are non-transformed.

total yields at Mount Vernon either year.

Differences in marketable yields were observed between cultivars and production systems at Knoxville both years, as well as an interaction $(P<$ 0.0001 ) in 2011 (Table 5). The reduced marketable yields at Knoxville in 2010 were due to losses from early cutworm feeding in high tunnels, as well as physiological tipburn. 'Coastal Star' had higher marketable yield compared with all other cultivars, except 'Green Star' in 2011. Additionally, average marketable yield in 2010 was higher $(P=0.0038)$ in open field compared with high tunnel plots. In contrast, results in 2011 showed that high tunnel marketable yields were higher $(P<0.0001)$ compared with open-field production and an interaction $(P<0.0001)$ between cultivar and production system was observed. The interaction can be largely attributed to lower romaine lettuce yields in the open field in $201 \mathrm{l}$ and transplanting $16 \mathrm{~d}$ earlier in the high tunnels in 2011 vs. 2010.

At Lubbock, average marketable yields were $55 \%$ and $45 \%$ higher than yields at Knoxville and Mount Vernon, respectively (Table 5). No diseases or insect damage resulted in yield losses at Lubbock, and though there were some wind-damaged outer leaves across all cultivars, these were removed before recording marketable weights. Cultivar differences were also observed both years $(P<0.0001$ and $P=$ 0.0195 , respectively), though not by production system. In both years, 'Jericho' and 'Coastal Star' had marketable yields greater than the other cultivars, except 'Green Star' in 2011. Only in 2010 was an interaction between cultivar and production system observed; higher marketable yields were observed with 'Green Star' in the open field, and premature bolting in the open field also reduced yields of 'Ermosa' and 'Adriana'.

Differences in marketable yields were not observed for cultivars, production system, or their interaction during 2010 at Mount Vernon (Table 5). However, marketable yields in both years were partly reduced because of infections by grey mold and lettuce drop. Cultivar differences $(P<$ 0.0001 ) were found in 2011 with the highest marketable yields observed for 'Green Star' followed by 'Coastal Star'. Yields of all other cultivars were similar. Additionally, there was an interaction $(P=0.0025)$ between cultivar and production system in 2011 as 'Green Star' had higher and 'Jericho' had lower marketable yields in the high tunnels. No other observable differences between high tunnel and open-field production systems were found. 
Table 5. Marketable yield of lettuce cultivars planted in high tunnel and open-field production systems in three regions of the United States (Knoxville, TN; Lubbock, TX; and Mount Vernon, WA) in 2010 and 2011.

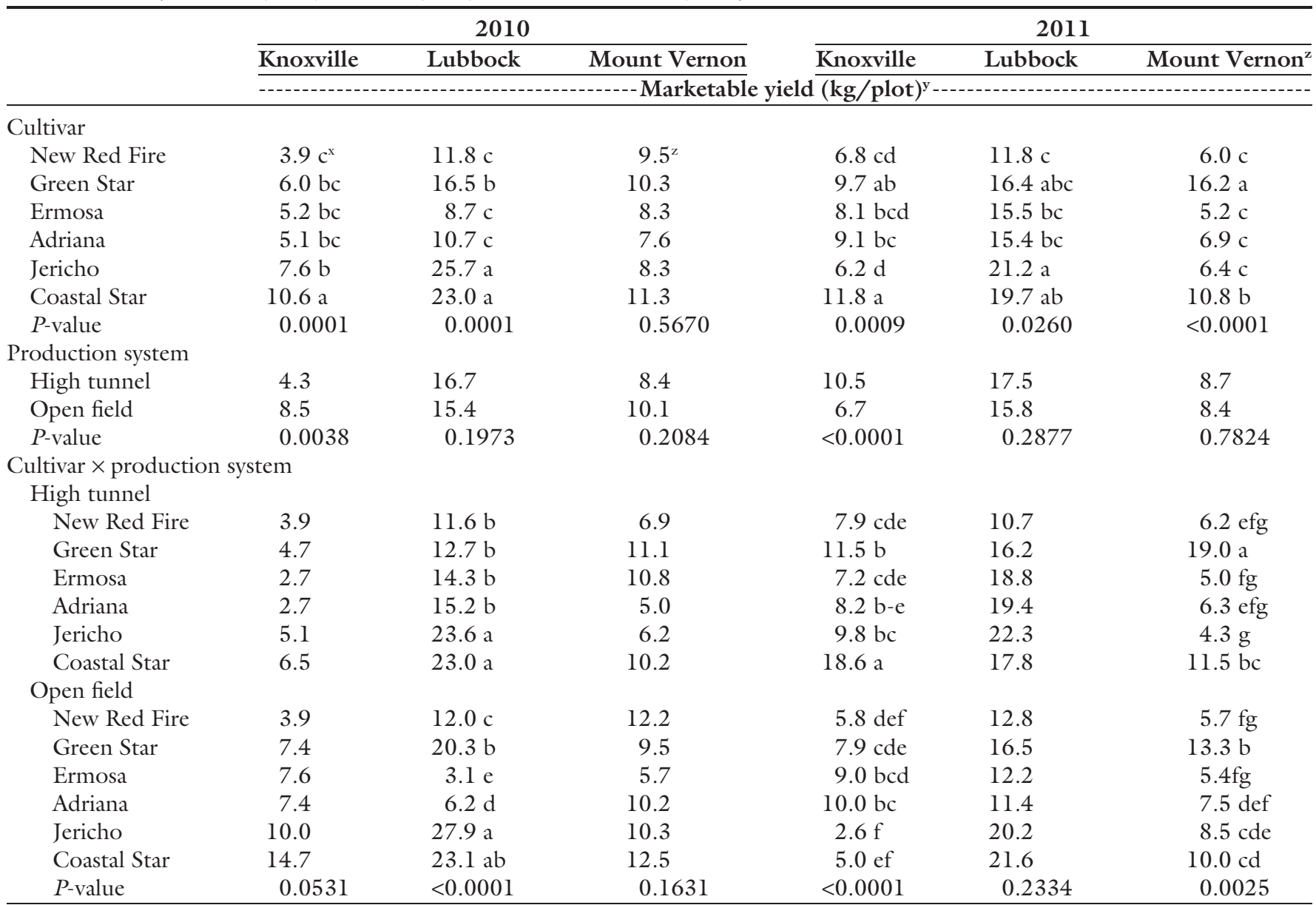

${ }^{\mathrm{z}}$ Mount Vernon marketable yield data for 2011 were square root transformed to meet the assumptions of normality. Data presented in this table are non-transformed. ${ }^{\mathrm{y}} \mathrm{l} \mathrm{kg}=2.2046 \mathrm{lb}$.

'Means within the same column for cultivar, production system, and cultivar $\times$ production followed by the same letter are not significantly different according to Fisher's protected least significant difference test at the 0.05 level.

In this study, overall marketable yields were negatively influenced by external factors within each diverse climate or location. At Knoxville, yields were reduced an average 46\% across years by cutworms, tipburn, and premature bolting, while at Mount Vernon disease reduced marketability by $51 \%$. Though no diseases or insects reduced lettuce marketability at Lubbock, high winds damaged the outer leaves and reduced yields by an average $6 \%$.

The different planting times between locations and production systems also influenced total and marketable yields. Although external factors such as diseases, insects, and wind may be difficult to control, especially in organic production, in general, planting dates usually are not. Depending on cultivar, lettuce planted from late May through September under high tunnel production varied in time to harvest and yield (Rader and Karlsson, 2006). However, Kelly (2005) and Zhao and Carey (2009) also reported that lowering temperatures inside high tunnels by adding shadecloth increased lettuce yield and quality. Transplanting lettuce too early in the open field in southern climates like Knoxville and Lubbock (frost free dates not until mid-April for both locations) may result in freeze or excessive wind injury and crop death. Transplanting lettuce 4 to 8 weeks earlier inside high tunnels in these two climates may help to mitigate these risks as long as other external factors can be controlled. At Mount Vernon, the high tunnel model used could not be erected before midApril because of moderate winds and saturated soils from precipitation experienced throughout the winter and early spring months in the region. A four-season high tunnel such as those used at Knoxville and Lubbock would likely have enabled earlier plantings, possibly resulting in greater differences in lettuce maturity dates.

Cultivar growth CHARACTERISTICS. Plant LDR at harvest is an indication of cultivar phenotype/ genotype characteristics. Leafy cultivars are typically short and wide with lower LDR values compared with taller romaine cultivars that typically have higher values. Higher LDR values at harvest in some cultivars may also be an indication of the initiation of premature bolting.

Overall, general cultivar characteristics remained consistent across production systems (data not shown). Cultivar LDR differences were observed at all three locations both years except at Mount Vernon during 2010 (Table 6). At Knoxville and Lubbock both years and at Mount Vernon in 2011, 'Coastal Star' had higher $(P<0.0001)$ LDR values compared 
Table 6. Length:diameter (ratio) of lettuce cultivars planted in high tunnel and open-field production systems in three regions of the United States (Knoxville, TN; Lubbock, TX; and Mount Vernon, WA) in 2010 and 2011.

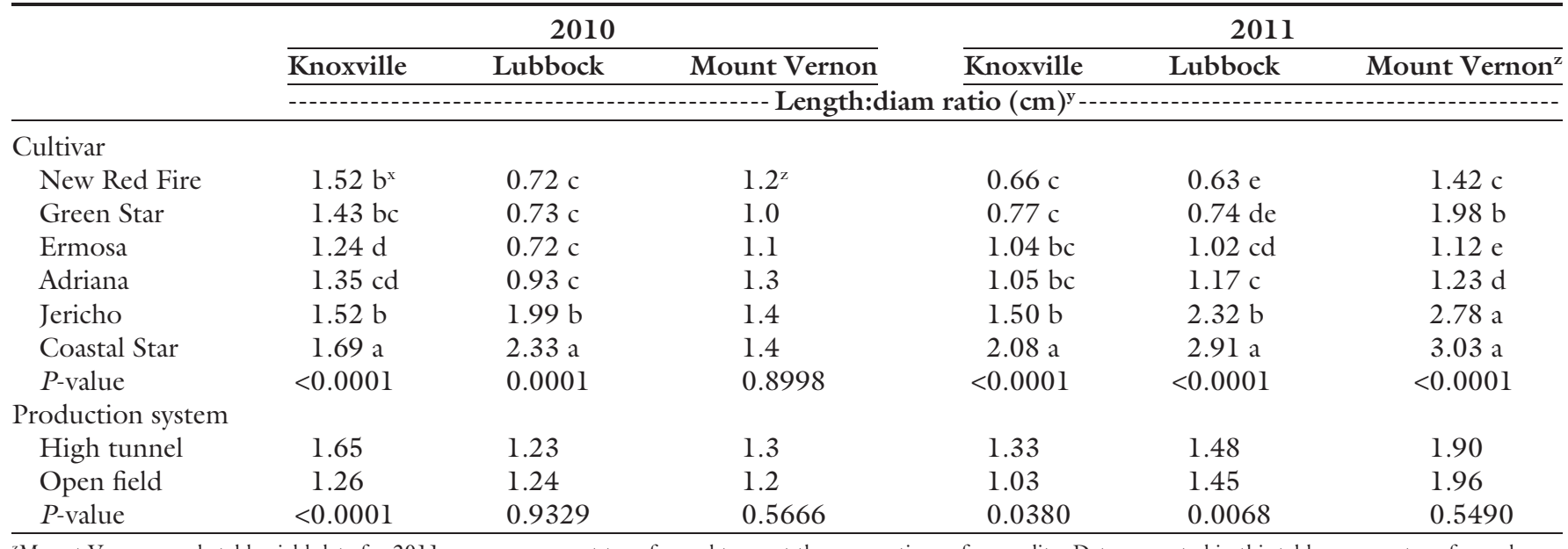

${ }^{\mathrm{z}}$ Mount Vernon marketable yield data for 2011 were square root transformed to meet the assumptions of normality. Data presented in this table are non-transformed.

${ }^{\mathrm{y}} 1 \mathrm{~cm}=0.3937$ inch.

${ }^{x}$ Means within the same column for cultivar, production system, and cultivar $\times$ production followed by the same letter are not significantly different according to Fisher's protected least significant difference test at the 0.05 level.

with the other cultivars, except at Mount Vernon in 2010. Butterhead cultivars (Ermosa and Adriana) grown at Knoxville in 2010 had LDR values lower than leafy cultivars, but in 2011, while not statistically significant, the reverse was observed. At Lubbock, romaine cultivars had higher LDR values $(P<0.0001)$ compared with the other cultivars both years. At Mount Vernon, there was no cultivar LDR response in 2010, but in 2011, the romaine cultivars had higher LDR values $(P<0.0001)$ than for the other types.

The results of this research suggest that in southern climates like Knoxville and Lubbock, high tunnels allow for earlier lettuce production during periods when the risk of freeze, wind damage, or both may occur. Earlier plantings inside high tunnels may reduce the risk of premature bolting but further research is needed at these locations to determine best planting dates and practices. In the maritime Pacific climate at Mount Vernon, higher temperatures and greater GDD accumulation in high tunnels decreased the time to harvest by only 1 or $2 \mathrm{~d}$; therefore, the economic profitability of high tunnel use for lettuce in that region needs careful consideration.

Total and marketable lettuce yield did not necessarily increase with high tunnel use; in fact, in 2010, high tunnel yields were lower at Knoxville and Mount Vernon because of negative biotic factors including insects and disease. Although the probability of premature bolting can be reduced by late winter/early spring planting in high tunnels, unseasonably high temperatures can also exacerbate bolting when planted inside at later dates. High tunnel use may be particularly advantageous to climates similar to the Texas High Plains, where high winds and blowing dust are common in the spring, though high tunnel selection and construction are critical to avoid structural damage. Use of four-season high tunnels at Mount Vernon may have allowed for earlier planting dates and resulted in different yield responses. Although planting dates, daylength, temperature, and production practices differed by location and could not be standardized in this experiment, and the fact that these factors likely influenced harvest times, yields, and quality, high tunnels appear to be effective tools for protecting lettuce from severe or adverse weather common in open-field production at all three locations, and thus, provide a useful alternative for earlier plantings.

\section{Literature cited}

Carey, E.E., L. Jett, W.J. Lamont, Jr., T.T. Nennich, M.D. Orzolek, and K.A. Williams. 2009. Horticultural crop production in high tunnels in the United States: A snapshot. HortTechnology 19:37-43.

Demchak, K. 2009. Small fruit production in high tunnels. HortTechnology 19:44-49.
Dennis, D.J. and W.M. Dulforce. 1974. Analysis of the subsequent growth and development of winter glasshouse lettuce in response to short periods in growth chambers during propagation. Acta Hort. 39:197-218

Dufault, R.J., B. Ward, and R.L. Hassell. 2006. Planting date and romaine lettuce cultivar affect quality and productivity. HortScience 41:640-645.

Hunter, B., D. Drost, and B. Black. 2012. Improving growth and productivity of early-season high tunnel tomatoes with targeted temperature additions. HortScience 47:733-740.

Kelly, K. 2005. Shade-covered high tunnels for summer production of lettuce and leafy greens. 5 July 2012 . <http:// ofrf.org/funded/reports/kelly_0ls36. pdf>.

Knewtson, S.J.B., E.E. Carey, and M.B. Kirkham. 2010. Management practices of growers using high tunnels in the central great plains of the United States. HortTechnology 20:639-645.

Lamont, W.J., Jr. 2009. Overview of the use of high tunnels worldwide. HortTechnology 19:25-29.

Lamont, W.J., Jr., M. McGann, M. Orzolek, N. Mbugua, B. Dye, and D. Reese. 2002. Design and construction of the Penn State high tunnel. HortTechnology 12:447-453.

Lang, G.A. 2009. High tunnel tree fruit production: The final frontier? HortTechnology 19:50-55.

Maynard, D. and G.J. Hochmuth. 1997. Knott's handbook for vegetable growers. 4th ed. Wiley, New York. 


\section{Research Reports}

Rader, H.B. and M.G. Karlsson. 2006. Northern field production of leaf and romaine lettuce using a high tunnel. HortTechnology 16:649-654.

Reeves, J. and D. Drost. 2012. Yields and soil quality under transitional organic high tunnel tomatoes. HortScience 47:38-44.

Simonne, A., E. Simonne, R. Eitenmiller, and C.H. Coker. 2002. Bitterness and composition of lettuce varieties grown in the southeastern United States. HortTechnology 12:721-726.

U.S. Department of Agriculture. 2011. USDA announces ranking dates for four major conservation initiatives. $5 \mathrm{Apr}$ 2012. <http://www.nrcs.usda.gov/wps/ portal/nrcs /detail/national/newsroom/ ?cid=STELPRDB1046002>.

Waterer, D. and J. Bantle. 2000. High tunnel temperature observations. 9 July 2012. <http://www.usask.ca/agriculture/ plantsci/vegetable/resources/veg/ht_ temp.pdf>

Wien, H.C. 2009a. Floral crop production in high tunnels. HortTechnology 19:56-60.

Wien, H.C. 2009b. Microenvironmental variations within the high tunnel. HortScience 44:235-238.
Wittwer, S.H. 1993. Worldwide use of plastics in horticultural production. HortTechnology 3:6-19.

Zhao, X. and E.E. Carey. 2005. Microclimate and reference crop evapotranspiration in high tunnels and open field during summer lettuce production. HortScience 40:1054-1055 (abstr.).

Zhao, X. and E.E. Carey. 2009. Summer production of lettuce, and microclimate in high tunnel and open field plots in Kansas. HortTechnology 19:113-119. 